\title{
Is the simple webbed penis a contraindication to circumcision?
}

\author{
Osama Abdullah Bawazir ${ }^{1,2^{*}}$ (D), Obada Alladh Alhallaq ${ }^{3}$, Bashair Albayhani ${ }^{3}$ and Abdullah Bawazir ${ }^{4}(\mathbb{0}$
}

\begin{abstract}
Background: Surgical correction of the webbed penis is challenging. We presented the safety and feasibility of webbed penis correction for neonates under local anesthesia using a simple principle of leaving equal cylindrical shaft skin.

Methods: This retrospective study included 530 patients who presented for circumcision to three pediatric surgery centers between May 2017 and January 2020. We included male patients aged less than four weeks old who had circumcision with a minimum of 6 months follow-up. We compared patients with normal penile anatomy $(n=451$, Group 1) to a simple webbed penis ( $n=79$, Group 2).

Results: There were no differences in age and weight between groups. The procedure time was significantly longer in Group 2 ( $8.05 \pm 3.11$ vs. $7.48 \pm 2.07 \mathrm{~min} ; P=0.04)$. There were no differences in bleeding $(P=0.38)$, redundant foreskin $(P>0.99)$, need for corrective surgery $(P=0.38)$, and re-suturing $(P=0.28)$ between groups. The procedure success was significantly higher in Group 1 (449 (99.56\%) vs. 70 (88.6\%); $P<0.001)$. Parents' satisfaction was measured at two weeks with no difference between both groups.
\end{abstract}

Conclusion: Simple penoscrotal web is not a contraindication for neonatal circumcision. Circumcision of the penoscrotal web had good esthetic results with comparable outcomes to those with a normal penis without a web.

Keywords: Circumcision, Web penis, Aesthetic outcomes

\section{Background}

Circumcision is a commonly performed procedure on neonates and infants worldwide [1,2], and in Saudi Arabia, it is estimated that $97 \%$ of male newborns are circumcised [3]. In patients with normal penile anatomy, the outcomes of circumcision are satisfactory $[4,5]$, while some surgeons consider circumcision is inappropriate in patients with a webbed penis $[6,7]$.

A skin fold tethers the scrotum to the ventral penis and obliterates the penoscrotal angle in patients with a webbed penis. Consequently, there is an abnormal attachment of the dartos fascia to the penile shaft with an abnormally short ventral shaft [8] . The webbed penis

\footnotetext{
*Correspondence: obawazir@yahoo.com; oabawazir@uqu.edu.sa ${ }^{1}$ Department of Surgery Faculty of Medicine in Umm Al-Qura University at Makkah, P.O.Box 715, Makkah 21955, Saudi Arabia

Full list of author information is available at the end of the article
}

may encompass a wide range of congenital deformities. Additionally, the condition may be associated with concomitant penoscrotal anomalies such as chordee, which causes further shortening of the ventral penis. Therefore, early surgical reconstruction of a penoscrotal web is recommended [9-11].

The penoscrotal web could be asymptomatic, and the condition is usually diagnosed during circumcision [12]. Surgical correction of the webbed penis in infancy had better long-term outcomes compared to adolescence repair [13]. Several studies have evaluated the outcomes of surgical repair of the primary (14) and post-circumcision (15) webbed penis. We aimed to present the safety and feasibility of webbed penis correction for neonates under local anesthesia using a simple principle of leaving equal cylindrical shaft skin. 


\section{Methods}

\subsection{Study design}

We performed a retrospective study including male neonates who presented for circumcision to three pediatric surgery centers between May 2017 and January 2020. We included male neonates less than four weeks old who had circumcision and a minimum follow-up of 6 months. The study flow diagram is presented in (Fig. 1).

For simplicity and proper planning of the surgical management, we classified the webbed penis into two

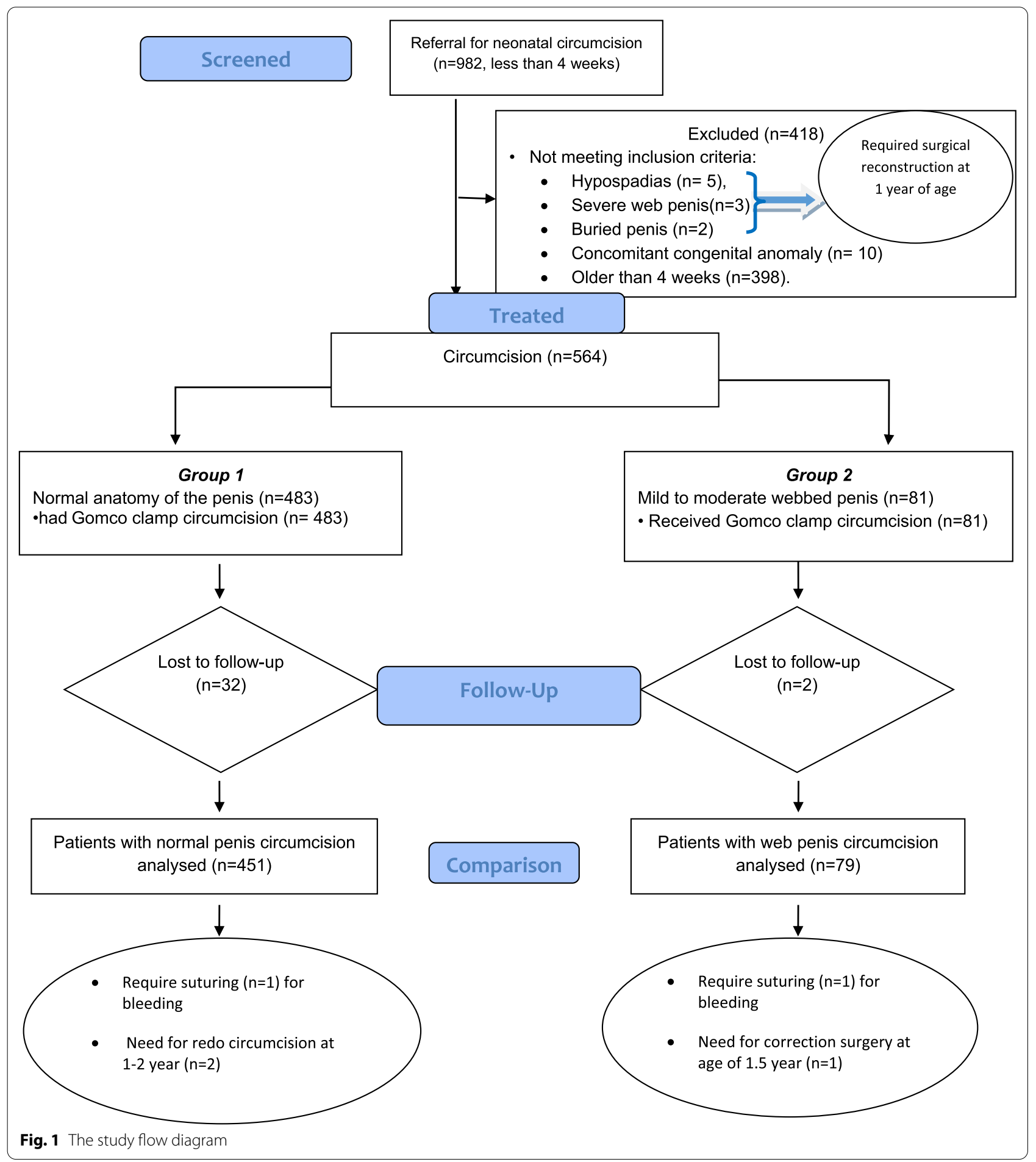


categories: simple and complicated (Fig. 2). The simple form is defined as tethering the scrotum skin to the ventral aspect of the penial body with normal urethra and erectile bodies. On the other hands, a complex webbed penis is associated with other anomalies, such as broad web, pre-penile scrotum, or penial curvature.

We obtained the approval of the Ethics Committee for the procedure and data collection of this study.

\subsection{Patients' assessment}

Circumcision was offered to neonates with body weights greater than two kilograms and those with no history of bleeding diathesis or severe systemic illness. The penile shaft should be more than three $\mathrm{cm}$ long and straight with no chordae or torsion. We examined the glans after retraction of the prepuce for the size and urethral meatus. The surfaces of the penis were examined for the normal penopubic crease, junction, and prominent corona ridge.

\subsection{Circumcision technique}

Circumcisions were performed using a Gomco clamp and a standardized technique. Emla topical cream was applied before the procedure for anesthesia. Marking was done to leave cylindrical skin with the same length around the penile shaft. In the group with normal anatomy, the incision was marked parallel to the corona ridge. In the webbed penis group, an oblique circumcision incision was marked with a slope up to give more ventral skin to compensate for the web. This oblique incision plan served to give equal cylindrical skin around the penial shaft (Fig. 3).

After the procedure, patients were kept under observation for $20 \mathrm{~min}$ in the recovery room. We followed the patients in the outpatient clinics after one week then after two and six months. Parents were educated about wound care, time to remove the dressing, and warning signs before discharge.

We used the modified Concodora Checklist to evaluate the suitability and success of neonatal clamp circumcision [16]. The checklist included the following: the circumcision site is located below the corona, the penile surfaces have equal cylindrical shaft skin and normal penoscrotal skin, and the glans penis has normal urethral meatus.

\subsection{Study data and endpoints}

We reported post-circumcision bleeding, infection, wound gaping, and urinary retention. Data about redundant foreskin (defined as the foreskin that completely covers the top of the penis when it's not erected), need for suturing, revision, or corrective surgery (indicated with persistent web or ventral skin tethering), and parents' satisfaction were recorded during follow-up. Parents responded to the question (Are you satisfied with the results of your child's circumcision? Yes/No.

\subsection{Statistical analysis}

We compared the baseline data and outcomes between the two groups. Quantitative data were presented as mean and standard deviation and compared using the

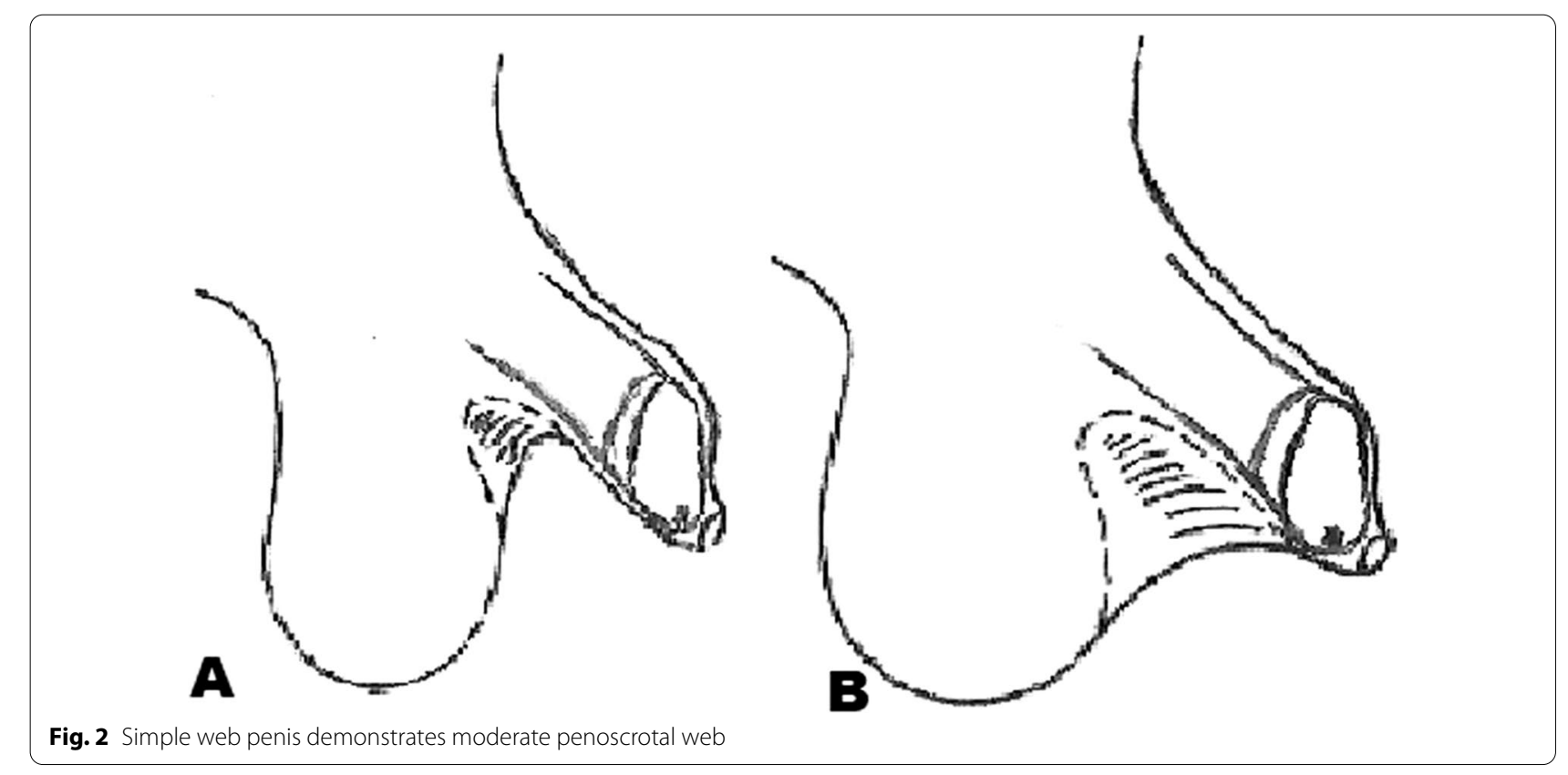



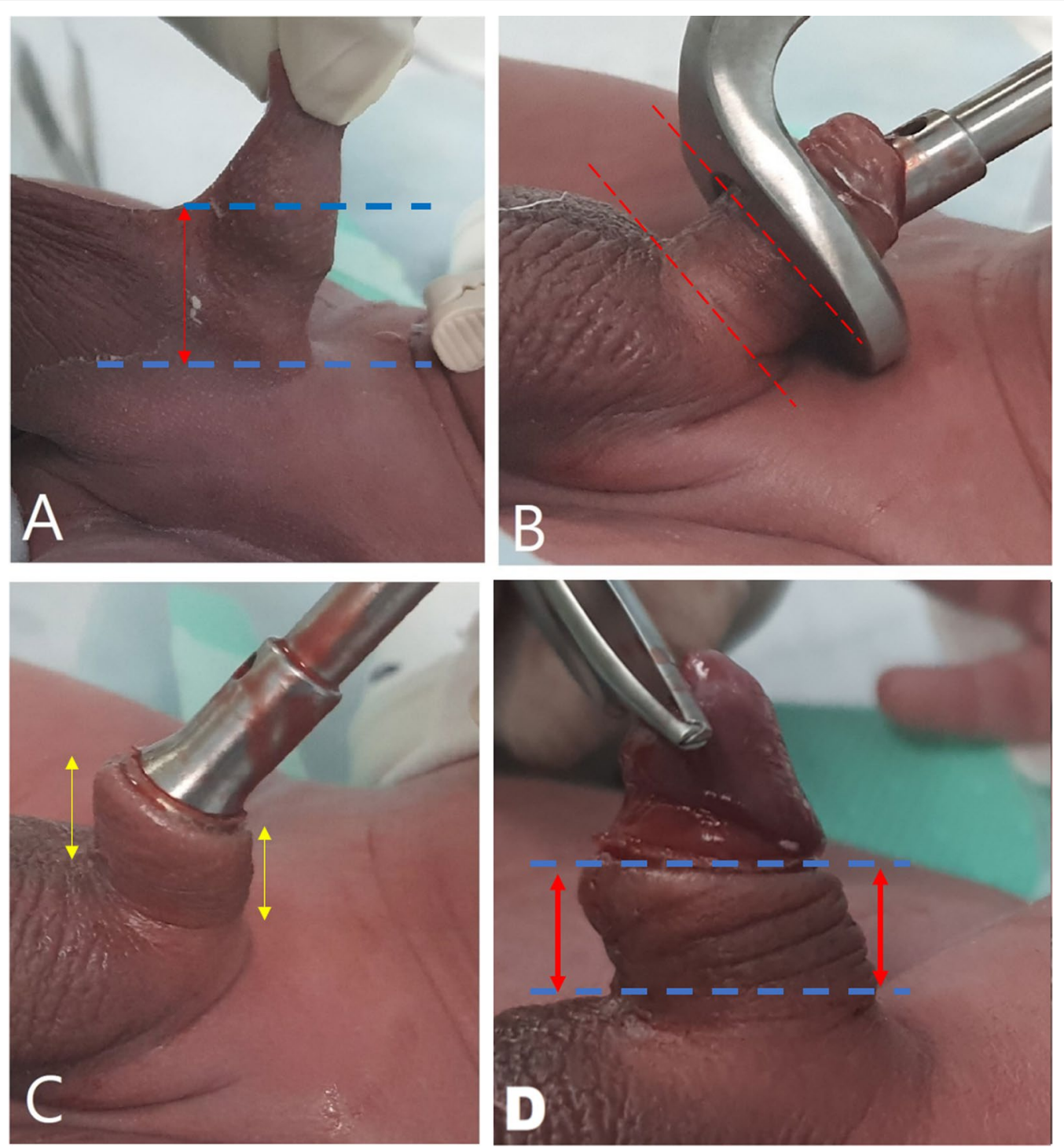

Fig. 3 Circumcision technique: A the discrepancy between the dorsal and ventral skin, B Gomco clamp was applied obliquely to have equal cylindrical shaft skin, $\mathbf{C}$ hemostasis was achieved. $\mathbf{D}$ the final appearance at the end of the procedure with even skin on both aspects

student $\mathrm{t}$ test. Qualitative data were analyzed using the Chi-square or Fisher exact test and presented as frequencies and percentages. We used Stata 16.1 to perform the analysis (Stata Corp- College Station- TX- USA), and a $\mathrm{P}$ value of less than 0.05 was considered statistically significant.

\section{Results}

Nine hundred eighty-two patients had circumcision, 452 were excluded, and 530 patients with complete postoperative follow-up were included in the present review. Eighty-one newborns had a simple webbed penis. We excluded patients with concomitant anomaly $(n=10)$ hypospadias with/without chordee $(n=5)$, complex webbed penis with penile curvature $(n=3)$, and buried penis $(n=2)$. Patients older than four weeks at the time of circumcision were excluded. We compared patients with normal penile anatomy ( $n=451$, Group 1$)$ to those with a simple webbed penis ( $n=79$, Group 2$)$.

\subsection{Baseline data}

The mean age in Group 1 was $13.53 \pm 8.02$ days and $14.24 \pm 7.15$ days in Group $2(P=0.46)$. There was no difference in weight between the two groups $(P=0.50)$. The duration of the procedure was significantly longer in Group $2(P=0.04)$ (Table 1$)$. 
Table 1 Comparison of the pre-circumcision data between neonates with normal penile anatomy and webbed penis

\begin{tabular}{lccc}
\hline & Group 1 $(\boldsymbol{n}=\mathbf{4 5 1})$ & Group 2 $(\boldsymbol{n}=\mathbf{7 9})$ & P value \\
\hline Age (days) & $13.53 \pm 8.02$ & $14.24 \pm 7.15$ & 0.46 \\
Weight (Kg) & $2.84 \pm 0.365$ & $2.87 \pm 0.34$ & 0.50 \\
$\begin{array}{l}\text { Procedure dura- } \\
\text { tion (minutes) }\end{array}$ & $7.48 \pm 2.07$ & $8.05 \pm 3.11$ & 0.04 \\
\hline
\end{tabular}

(Data were presented as mean and standard deviation, comparison was made using t-test) Group 1: Neonates with normal penile anatomy Group 2: Neonates with simple webbed penis

\subsection{Postoperative outcomes}

There were no differences in bleeding $(P=0.38)$, redundant foreskin $(P=1)$ and suturing $(P=0.28)$ between groups. Two patients had redo circumcision in Group $1(0.4 \%)$, and one patient (1.2\%) had corrective surgery (Heineke-Mikulicz scrotoplasty) at 1.5 years in Group 2. No patient had urine retention in both groups. The procedure success was significantly higher in Group 1 (449 (99.56\%) versus 70 (88.6\%); $P<0.001)$. Parents' satisfaction was measure at two weeks with no difference between both groups. (Table 2).

\section{Discussion}

Webbed penis has been studied in the literature under different nomenclatures, including the buried penis, penoscrotal webbing or fusion, the inconspicuous penis, penoscrotal pterygium, and penis palmatus (17). Usually, this condition becomes problematic when circumcision is requested and could lead to psychological trauma because of the abnormal appearance; therefore, early addressing this condition is highly recommended. The penoscrotal web is usually asymptomatic and discovered during circumcision; however, some patients could present with pain, abnormal urine stream, or sexual dysfunction if left untreated [17].

The etiology of the webbed penis is unclear; a hypothesis attributed this to the abnormal development of the prepuces leading to inadequate skin coverage of the ventral penis and, consequently, borrowing scrotal tissue [18].

A classification for penoscrotal fusion was proposed [8]. Their classification spectrum included buried, trapped, webbed, and micropenis. El-Koutby and associates [15] further divided the webbed penis into simple, compound, primary, and secondary. Several studies correlated the complexity of the repair to the severity of the webbed penis [8]; however, other studies argued that ElKoutby's classification of the webbed penis is not related to the complexity of repair or the approach $[9,10]$. Our research found that the simple form of the webbed penis with a moderate penoscrotal web is common (Fig. 4). Almost all simple webbed penis can be managed at the neonatal period with a simple modification, which is in agreement with Maizels and associates' study [14]. They reported a success rate of $99 \%$ in 297 patients with a webbed penis using a Mogen clamp and an oblique incision, slant up, to the corona ridge to compensate for the web.

The complex webbed penis needs surgical reconstruction. Several methods are available for surgical treatment of the penoscrotal web [19-21], and recent attempts were made to simplify the repair [10, 22, 23]. However, no available studies are comparing these techniques. Literature review revealed several techniques described to correct the penoscrotal web at the time of circumcision to prevent iatrogenic penoscrotal tethering. Z-plasty techniques, rotational flaps, inverted $Y$, and complete exteriorization of the shaft have all been proposed as different approaches to correct the skin deformity [24-26]. Most of the techniques described to correct the webbed penis require general anesthesia and are usually done after six months. However, our technique is simple and can be done in the neonatal period in the outpatient clinic without general anesthesia and with excellent esthetic results.

Circumcision may be contraindicated in some cases of the webbed penis, especially in those with concomitant anomalies and in severe forms. During the circumcision of the mild degree of the webbed penis, excessive ventral

Table 2 Comparison of the post-circumcision data between neonates with normal penile anatomy and webbed penis

\begin{tabular}{lllc}
\hline & Group 1 $(\boldsymbol{n = 4 5 1 )}$ & Group 2 (n= 79) & P value \\
\hline Bleeding & $2(0.4 \%)$ & $1(1.2 \%)$ & 0.38 \\
Need for redo/corrective surgery & $2(0.4 \%)$ & $1(1.2 \%)$ & 0.38 \\
Success & $449(99.56 \%)$ & $70(88.6 \%)$ & $<0.001$ \\
Redundant foreskin & $2(0.4 \%)$ & 0 & 0.999 \\
Suturing for bleeding & $1(0.2 \%)$ & $1(1.14 \%)$ & 0.28 \\
Parent satisfaction at 2 weeks & $413(91.57 \%)$ & $70(88.6 \%)$ & 0.39 \\
\hline
\end{tabular}

(Data were presented as frequencies and percentages, comparison was made using the Chi-square or Fisher exact test if the expected frequency was less than 5 )

Group 1: Neonates with normal penile anatomy Group 2: Neonates with simple webbed penis 

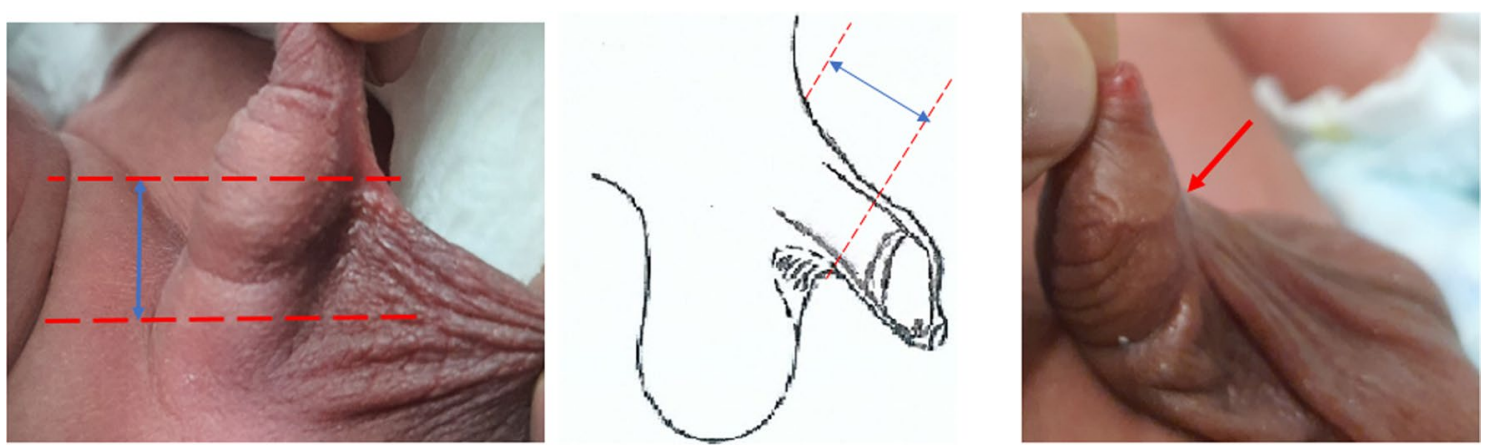

Fig. 4 Simple web penis demonstrates moderate penoscrotal web

skin should be left for surgical correction of the condition. We believe a simple webbed penis can be managed by making the cutting plan in an oblique angle to compensate for the ventral skin during circumcision using skin marking "formation of an oblique incision line for the outer leaf of the foreskin." A technique that was originally described by Senaylı and colleagues [23] and followed by Maizels and associates [14]. Similar to our study, these studies report good outcomes with excellent esthetic results in most cases.

In this study, we reported promising results for circumcision of a simple webbed penis with Gomco clamp obliquely with a low complication rate compared to the circumcision of the normal penis. Similar findings were reported in other studies with good cosmetic results and low complication rates [19, 20]. Negm and colleagues reported two methods to repair webbed penis using scrotoplasty or multiple Z-plasty. Wound infection occurred in two $(4.5 \%)$ patients in the scrotoplasty group. Postoperative mild penile edema occurred in three patients (11.1\%) in the Z-plasty group, and two patients had a hematoma [20].

Contrary to Maizels' study, we did not report a need for penis shaft skin physical therapy (PSSPT) because the weight of the scrotal sac pulls the web skin down and gives a normal-looking shaft within few months of circumcision. In Maziels' study, PSSPT was applied after circumcision to push down the shaft skin to encourage the shaft skin to anchor at the penis base and mitigate the web [14].

\subsection{Study limitations and strength}

The study's main limitation is the retrospective design. We included patients with a simple webbed penis only, and the results cannot be generalized to all types of webbed penis. On the other hands, this is a multicenter study that included a relatively large patients number compared to other studies. The follow-up duration was limited to six months, and more extended follow-up studies are recommended.

\section{Conclusions}

The simple penoscrotal web is not a contraindication for neonatal circumcision. Circumcision of the penoscrotal web had good esthetic results with comparable outcomes to those with a normal penis without a web.

\section{Acknowledgements \\ I would like to express my deep gratitude to Miss Razan Bawazir for her valu- able support on photo editing in this article.}

\section{Authors' contributions}

$\mathrm{OB}$ and $\mathrm{OA}$ made the study design. $\mathrm{OA}$ did extensive literature review, analyzed, and interpreted the patient data regarding the webbed penis correction for neonates under local anesthesia. BA and AB performed the data collection and were a major contributor in writing the manuscript. OB was supervise the other junior authors and did the final revision and correction of the manuscript. All authors contributed to the conception or design of the work and/or the acquisition, analysis, and interpretation of data. Drafts were revised critically for important intellectual content, and the final version was approved by all. All agree to be accountable for all aspects of the work and have read and approved the final manuscript.

\section{Funding}

None.

\section{Availability of data and materials}

The datasets generated and/or analyzed during the current study are not publicly available due [patient confidentiality policy in our institution] but are available from the corresponding author on reasonable request.

\section{Declarations}

Ethics approval and consent to participate

All procedures performed in studies involving human participants were in accordance with the ethical standards of the institutional and/or national research committee and with the 1964 Helsinki declaration and its later amendments or comparable ethical standards. Approval of research was given by the Institutional Biomedical Ethical Committee, Faculty of Medicine, Um Al Qura University-Makkah-KSA [Approval No.(HAPO-02-K-012-2021-04-662)]. We obtained the approval of the Ethics Committee for the procedure and data collection of this study. Verbal consent was obtained from the parents of all patients included in the study. 


\section{Consent for publication}

Written informed consent for the publication of this data was given by the patients' parents or their legal guardians.

\section{Competing interests}

The authors declare that they have no competing interests.

\section{Author details}

${ }^{1}$ Department of Surgery Faculty of Medicine in Umm Al-Qura University at Makkah, P.O.Box 715, Makkah 21955, Saudi Arabia. ${ }^{2}$ Department of Surgery, Section of Pediatric Surgery, International Medical Center Hospital, Jeddah, Saudi Arabia. ${ }^{3}$ Department of Surgery, Section of Pediatric Surgery, International Medical Center Hospital, Jeddah, Saudi Arabia. ${ }^{4}$ College of Medicine, King Saud Bin Abdulaziz University for Health Sciences, Jeddah, Makkah, Saudi Arabia.

Received: 14 May 2021 Accepted: 25 August 2021

Published online: 19 September 2021

\section{References}

1. Weiss HA, Larke N, Halperin D, Schenker I (2010) Complications of circumcision in male neonates, infants and children: a systematic review. BMC Urol 16(10):2. https://doi.org/10.1186/1471-2490-10-2

2. Bawazir OA, Banaja AM (2020) Sutureless versus interrupted sutures techniques for neonatal circumcision; a randomized clinical trial. J Pediatr Urol 16(4):493.e1-493.e6. https://doi.org/10.1016/j.jpurol.2020.06.025 (Epub 2020 Jun 25)

3. Morris BJ, Wamai RG, Henebeng EB, Tobian AA, Klausner JD, Banerjee J, Hankins CA (2016) Estimation of country-specific and global prevalence of male circumcision. Popul Health Metr 1(14):4. https://doi.org/10.1186/ s12963-016-0073-5.Erratum.In:PopulHealthMetr.2016;14:11

4. - Perera CL, Bridgewater FH, Thavaneswaran P, Maddern GJ. Safety and efficacy of nontherapeutic male circumcision: a systematic review. Ann Fam Med. 2010 8(1):64-72. https://doi.org/10.1370/afm.1073. PMID: 20065281

5. El Bcheraoui C, Zhang X, Cooper CS, Rose CE, Kilmarx PH, Chen RT (2014) Rates of adverse events associated with male circumcision in U.S. medical settings 2001 to 2010. JAMA Pediatr 168(7):625-634. https://doi.org/10. 1001/jamapediatrics.2013.5414

6. Mayer E, Caruso DJ, Ankem M, Fisher MC, Cummings KB, Barone JG (2003) Anatomic variants associated with newborn circumcision complications. Can J Urol 10(5):2013-2016

7. Simpson E, Carstensen J, Murphy P (2014) Neonatal circumcision: new recommendations \& implications for practice. Mo Med 111(3):222-230

8. Srinivasan AK, Palmer LS, Palmer JS (2011) Inconspicuous penis. ScientificWorldJournal 11:2559-2564. https://doi.org/10.1100/2011/238519 (Epub 2011 Dec 29)

9. Bonitz RP, Hanna MK (2016) Correction of congenital penoscrotal webbing in children: a retrospective review of three surgical techniques. J Pediatr Urol 12(3):161.e1-5. https://doi.org/10.1016/j.jpurol.2016.02.003 (Epub 2016 Feb 19)
10. McLeod DJ, Alpert SA (2014) Double-V scrotoplasty for repair of congenital penoscrotal webbing: a hidden scar technique. J Pediatr Urol 10(5):810-814. https://doi.org/10.1016/j.jpurol.2014.01.014 (Epub 2014 Feb 13)

11. Cho KS (2016) Webbed penis. In: Park N, Kim S, Moon D (eds) Penile augmentation. Springer, Berlin, Heidelberg

12. Redman JF (1985) A technique for the correction of penoscrotal fusion. J Urol 133(3):432-433. https://doi.org/10.1016/s0022-5347(17)49008-2

13. Herndon CD, Casale AJ, Cain MP, Rink RC (2003) Long-term outcome of the surgical treatment of concealed penis. J Urol 170:1695-1697. https:// doi.org/10.1097/01.ju.0000083911.59937.c6 (Discussion 1697)

14. Maizels M, Meade P, Rosoklija I, Mitchell M, Liu D (2019) Outcome of circumcision for newborns with penoscrotal web: oblique skin incision followed by penis shaft skin physical therapy shows success. J Pediatr Urol 15(4):404.e1-404.e8. https://doi.org/10.1016/j.jpurol.2019.05.021 (Epub 2019 May 27)

15. El-Koutby M, Amin MA (2010) Webbed penis: a new classification. J Indian Assoc Pediatr Surg 15(2):50-52. https://doi.org/10.4103/0971-9261.70637

16. Concodora CW, Maizels M, Dean GE, Weiss DA, Alpert SA, Edmondson JD, Elder JS, Herndon A, Elmore JM, Rychlik K (2016) Checklist assessment tool to evaluate suitability and success of neonatal clamp circumcision: a prospective study. J Pediatr Urol 12(4):235.e1-5

17. Perlmutter AD, Chamberlain JW (1972) Webbed penis without chordee. J Urol 107(2):320-321. https://doi.org/10.1016/s0022-5347(17)61016-4

18. Bergeson PS, Hopkin RJ, Bailey RB Jr, McGill LC, Piatt JP (1993) The inconspicuous penis. Pediatrics 92(6):794-799

19. Macedo A Jr, Ottoni SL, Garrone G, de Mattos RM, da Cruz ML. A simple way to treat penile concealing due to webbed penis. Int Braz J Urol. 2021 47(1):220-221. doi: https://doi.org/10.1590/S1677-5538.IBJU.2019.0798. PMID: 33047937; PMCID: PMC7712694.

20. Negm MA, Nagla SA (2020) Surgical management of post-circumcision webbed penis in children. Arab J Urol 18(2):101-110

21. Shapiro SR (1987) Surgical treatment of the "buried" penis. Urology 30(6):554-559. https://doi.org/10.1016/0090-4295(87)90435-3

22. Borsellino A, Spagnoli A, Vallasciani S, Martini L, Ferro F (2007) Surgical approach to concealed penis: technical refinements and outcome. Urology 69(6):1195-1198. https://doi.org/10.1016/j.urology.2007.01.065

23. Senaylı A, Senaylı Y (2010) A novel operative technique for concealed penis secondary to penoscrotal web: a case report. Ther Adv Urol 2(5-06):215-218. https://doi.org/10.1177/1756287210390410

24. Alter GJ (2007) Correction of penoscrotal web. J Sex Med 4(4 Pt 1):844847. https://doi.org/10.1111/j.1743-6109.2007.00512.x

25. Chen YB, Ding XF, Luo C, Yu SC, Yu YL, Chen BD, Zhang ZG, Li GH (2012) A new plastic surgical technique for adult congenital webbed penis. J Zhejiang Univ Sci B 13(9):757-760. https://doi.org/10.1631/jzus.B1200117

26. Zaontz MR (2006) Surgical management of the concealed penis with a penoscrotal web. Dialog Pediatr Urol 28:8

\section{Publisher's note}

Springer Nature remains neutral with regard to jurisdictional claims in published maps and institutional affiliations.

\section{Submit your manuscript to a SpringerOpen ${ }^{\circ}$ journal and benefit from:}

- Convenient online submission

- Rigorous peer review

- Open access: articles freely available online

- High visibility within the field

- Retaining the copyright to your article

Submit your next manuscript at $\boldsymbol{\Delta}$ springeropen.com 